\title{
Role of Milrinone on Oxygen Index in Babies Ventilated for Meconium Aspiration Syndrome
}

\author{
Najmus Saqib ${ }^{1 *}$, Mahvish Qazi ${ }^{2}$, Narayanappa $^{3}$, Srinivasamurty Doreswami ${ }^{3}$ \\ ${ }^{1}$ Department of Paediatrics and Neonatology, SKIMS Soura Srinagar Kashmir, India \\ ${ }^{2}$ Department of Obstetrics and Gynaecology, SKIMS Soura Srinagar Kashmir, India \\ ${ }^{3}$ JSS Medical College, Mysore, Karnataka, India
}

Submission: January 23, 2017; Published: February 20, 2017

*Corresponding author: Dr. Najmus Saqib, Senior Resident, Department of Paediatrics and Neonatology, SKIMS Soura Srinagar, India, Tel: 91-9419215329; Email: shstar321@gmail.com

\begin{abstract}
Background: Meconium aspiration syndrome (MAS) is a common problem that most paediatricians will encounter in the delivery room and normal newborn nursery. The aim this study was to evaluate the role of Milrinone on oxygen index in babies ventilated for MAS.

Material and Methods: This randomized controlled study was carried on 30 babies admitted in NICU with MAS within 24 hours of life on ventilator with Oxygen index $\geq 8$. Patients were randomized by serially numbered opaque sealed envelope (SNOSE) method either to undergo milrinone via slow iv infusion pump along with standard management or to receive standard management of MAS in 1:1 equal allocation ratio. Milrinone was given for a maximum of 48 hours and the efficacy of the same was studied in terms of improvement in ventilator parameter i.e. Oxygen index (OI).

Results: There was no statistically significant improvement of $\mathrm{OI}$ in the milrinone group at $0,12,24,48$ hours when compared to the control group with $\mathrm{p}=0.9, \mathrm{p}=0.96, \mathrm{p}=0.9, \mathrm{p}=0.78$ at $0,12,24,48$ hours respectively. Mean duration of mechanical ventilation, was more in milrinone group compared to the control group $(3.89 \mathrm{v} / \mathrm{s} 3.33)$ with $\mathrm{p}$ value of 0.9 . Mortality during the hospital stay was noticed to be lesser in milrinone group compared to non-milrinone group. There were no complications in any of the babies associated with administration of milrinone.
\end{abstract}

Conclusion: Milrinone didn't prove to be effective in improving oxygen index in babies ventilated for MAS. Babies on milrinone didn't show any improvement in duration of respiratory support. Mortality during the hospital stay was lesser in milrinone group.

\section{Introduction}

Meconium aspiration syndrome (MAS) is a common problem that most pediatricians will encounter in the delivery room and normal newborn nursery. The overall frequency of MSAF varies between $5 \%$ to $25 \%$ and usually occurs in term or post-term infants [1]. Meconium aspiration syndrome remains one of the most common causes of neonatal respiratory distress [2]. Meconium stained amniotic fluid, as a result of passage of fetal colonic contents into the amniotic cavity, is noted in approximately $12 \%$ of all deliveries. Meconium aspiration syndrome (MAS) is noted in $5 \%$ of these infants, $30 \%$ of them require mechanical ventilation, more than $4 \%$ of MAS infants die accounting for $2 \%$ of all perinatal deaths $[3,4]$. In utero, meconium passage rarely occurs before 32 weeks of gestation and most babies with meconium stained amniotic fluid are 37 weeks or older [5]. Usually, but not invariably, fetal distress and hypoxia occur before the passage of meconium into amniotic fluid. These infants are meconium stained and may be depressed and require resuscitation at birth [6].

According to working definitions of the National NeonatalPerinatal Database of India: MAS should be diagnosed if any two of the following three criteria are present:

A.Meconium staining of liquor or staining of nails or umbilical cord or skin.

B.Respiratory distress soon after birth, within one hour of birth.

C.Radiological evidence of aspiration pneumonitis (atelectasis) and/or Hyperinflation [7].

Acute or chronic hypoxia and/or infection can result in the passage of meconium in utero. In this setting, gasping by the fetus 
or newly born infant can cause aspiration of the amniotic fluid contaminated by the Meconium [8]. Meconium aspiration before or during birth can obstruct airways, interfere with gas exchange, decreases lung compliance, causing alveolar oedema, chemical pneumonitis, and pulmonary hypertension9. Clinical studies show that pulmonary artery hypertension is always associated in the pathogenesis of severe neonatal MAS which often results in fatal complications. This is generally attributed to increased resistance of a normal pulmonary vascular bed in response to perinatal hypoxia and acidosis $[9,10]$. Many trials have shown significant improvement in oxygen index with administration of Milrinone. The aim of this study was to know the effect on oxygen index after administration of milrinone in hypoxic babies ventilated for MAS.

\section{Objective of the Study}

Primary Objective: To study the effect of Milrinone on oxygen index in babies ventilated for MAS.

\section{Secondary objectives:}

a.To study the duration of respiratory support in babies with milrinone and without milrinone

b.To compare the mortality rate between MAS ventilated babies with and without milrinone.

\section{Materials and Methods}

The study was a randomized controlled study conducted in the NICU of JSS Hospital Mysore during the study period - May 2011 to September 2013.

Source of data: Neonates admitted in NICU with Meconium aspiration syndrome on ventilator with oxygen index of $\geq 8$ [11] were included .After fulfilling the criteria, patients were randomized by a serially numbered opaque sealed envelope (SNOSE) method either to undergo milrinone via slow IV infusion pump along with standard management or to receive standard management of MAS in 1:1 equal allocation ratio.

PALS guidelines 2011: Loading dose of 50 microgram $/ \mathrm{kg}$ administered over 10-60 followed by continuous infusion over of $0.25-0.75 \mathrm{microgram} / \mathrm{kg} / \mathrm{minute}$.

Group A (Study group): These neonates were given milrinone via slow IV infusion pump along with standard management. Milrinone was given for a maximum of 48 hours.

Group B (Control group): These neonates were given standard management of MAS.

In both groups, babies were continuously monitored and blood gases done at $0,12,24$ and 48 hours after initiating treatment.

$\mathrm{OI}=\mathrm{FiO} 2 \mathrm{X}$ MAP X 100/ PaO2

\section{Method of collection of data}

\section{Inclusion Criteria}

Term neonates with Meconium aspiration syndrome requiring ventilator support with oxygen index of $\geq 8$ within 24 hours of life.

\section{Exclusion Criteria}

a. Babies with respiratory distress syndrome other than MAS are excluded

b. Babies with MAS referred from other hospitals after 24 hours of age.

c. Babies having surgical problems needing immediate surgical interventions

d. Babies with acute renal failure.

\section{Ventilation Criteria}

a) Baby born with meconium aspiration with poor respiratory efforts.

b) Baby born with meconium aspiration with severe respiratory distress requiring $\mathrm{PaO} 2>40 \%$ to maintain saturation above $93 \%$.

c) Baby born with meconium aspiration with blood gas showing hypoxemia and hypercarbia with acidosis (either respiratory or metabolic).

\section{Parameters to be studied}

Primary outcome: Difference in oxygen index after $0 \mathrm{hr}, 12 \mathrm{hr}$, $24 \mathrm{hr}$, and $48 \mathrm{hr}$ in both groups.

\section{Secondary outcome:}

A.Difference in duration of respiratory support in both groups.

B.Difference in the mortality rate in both the groups.

\section{Statistical methods}

Descriptive statistics is done measuring mean, median and standard deviation. Inferential statistics is done by using Mann Whitney test (to compare median of two independent groups), chisquare test (to compare independent proportions). P value $<0.05$ is considered as statistically significant. All statistical calculations are done using SPSS version 13.0. Graphical presentation was done by using Microsoft Excel.

Results

Mean OI at admission is $13.72 \mathrm{v} / \mathrm{s} 12.99 \mathrm{p}=0.9$ no statistical significant difference at $12 \mathrm{hrs} 0 \mathrm{I}=8.97 \mathrm{~V} / \mathrm{S} 8.80 \mathrm{p}=0.96$, at $24 \mathrm{hrs}$ $\mathrm{OI}=6.73 \mathrm{~V} / \mathrm{S} 6.34 \mathrm{p}=0.96$, at $48 \mathrm{hrs} \mathrm{OI}=5.59 \mathrm{~V} / \mathrm{S} 4.85 \mathrm{p}=0.78$ which has statistically no difference in each session or duration in the OI of both the group. No differential decrease in the OI in the case group compared to the control group. Mean ventilator days $=3.89$ $\mathrm{v} / \mathrm{s} 3.33$ with no statistical difference in the birth weight of cases and controls as the $\mathrm{p}$ value is 0.9 . Mean Oxygen days $=2.8 \mathrm{v} / \mathrm{s}$ 1.67 with no statistical difference in the birth weight of cases and controls as the $\mathrm{p}$ value is 0.65 .

Mean total respiratory support (Oxygen days+ ventilator days) $=6.67 \mathrm{v} / \mathrm{s} 5$ with no statistical difference in the total respiratory support and controls as the p value is 0.74 . Mortality during the hospital stay was noticed to be lesser in milrinone group (One) 
compared to non-milrinone group (Three).One baby died due to ventilator associated pneumonia with sepsis (milrinone group).In non milrinone group, 3 babies died with sepsis/DIC/Pulmonary hemorrhage. There was no complication in any of the babies associated with administration of milrinone (Figure 1).

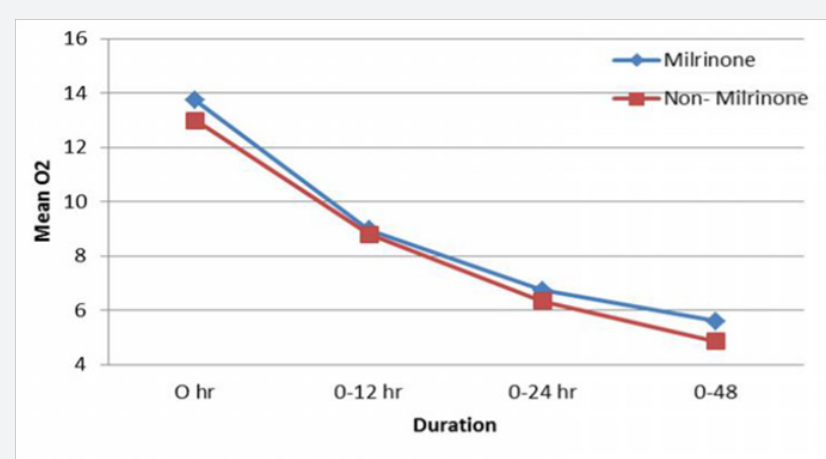

Figure 1

\section{Discussion}

Milrinone is a selective phosphodiesterase inhibitor which has positive inotropic, vasodilator action and mild chronotrophic action [11-23]. Used as an adjunct to nitric oxide in patients with persistent pulmonary hypertension of newborn, low cardiac output (especially after cardiac surgery) [24] and in septic shock [25]. There is some evidence for its use in preventing low cardiac output in patients undergoing cardiac surgery. It is for short term treatment only and should generally not be used for longer than 72 hours [12,21].

It acts on pulmonary vasculature by decreasing systemic vascular resistance, increasing cardiac contractility and cardiac output [26]. By reducing pulmonary after load, improving RV compliance and increasing myocardial contractility, milrinone improves passive left ventricular filling hence increased cardiac output and blood pressure stability [27].

Milrinone is a bipyridine compound that selectively inhibits PDE III. In a pediatric rodent model of hypoxia-induced pulmonary hypertension, the expression of PDE IIIa is up-regulated, and pulmonary artery relaxation is increased with milrinone treatment [28]. Experience with this drug in neonates is limited. Early studies of milrinone suggested that it was a relatively ineffective inotrope in a neonatal rabbit experimental model [29] and speculated that postnatal maturation of affinity occurred; however, in neonatal canine and porcine models, positive inotropy was demonstrated in the neonatal heart $[30,31]$.

We identified only few studies that quantified for this review.

\section{First Cochrane Neonatal Review}

The objective of study was to compare, assess efficacy and safety in infants with PPHN either treated with: milrinone compared with placebo or no treatment; milrinone compared with iNO; milrinone as an adjunct to iNO compared with iNO alone; milrinone compared with potential treatments for PPHN other than iNO. The author conclusion is the efficacy and safety of milrinone in the treatment of PPHN are not known and its use should be restricted within the context of RCTs. In our study also Milrinone didn't prove to be effective in improving oxygen index in babies ventilated for MAS (PPHN a known complication) [32].

\section{Second Pilot studies:}

A.Bassler on 4 neonates revealed improvement in oxygen index. However out of 4 babies 2 develop severe IVH and one small IVH [33].

B.Another study done in Korea by Doo-KyoIn, M.D SungWan Yang et al on 6 neonates revealed Milrinone proved to be effective in improving oxygen index [34].

C.McNamara PJ et al on nine full term neonates also revealed early improvements in oxygen index with milrinone [35].

There were no complications in babies in the last two pilot studies associated with the administration of milrinone. Currently a study on pharmacokinetic data of milrinone of infants with PPHN are currently collected (kirplani) [36].

\section{Conclusion}

A.Milrinone didn't prove to be effective in improving oxygen index in babies ventilated for Meconium Aspiration syndrome compared to non-milrinone group.

B.Babies on milrinone didn't show any improvement in duration of respiratory support.

C.Mortality during the hospital stay was lesser in milrinone group.

1)Serial ECHO evaluation for pulmonary hypertension couldn't be done to know the effect of milrinone on pulmonary pressure.

2)Long term morbidity couldn't be determined.

3)Study needs to be done on large number of sample size.

\section{References}

1. Meharban Singh (2004) Respiratory Disorders. In: Chapter 19, Care of the New Born, 6th edition, Sagar Publications, New Delhi pp. 263.

2. Wiswell TE, Bent RC (1993) Meconium staining and the MAS. Pediatr Clin North Am 40: 955.

3. Kemmeth J, Trimmer (1991) Meconium and birth asphyxia. Am J Obstet Gynecol 65(4): 1010-1013.

4. Pravin Goud, Usha Krishna (1989) Significance of meconium staining of amniotic fluid in labour. Indian J of Obs Gyn 39(4): 523-526.

5. Usher RH, Boyd ME, McLean FH (1988) Assessment of fetal risk in postdate pregnancies. Am J Obstet Gynecol 158(2): 259-264.

6. Kliegman: Nelson Textbook of Pediatrics, $\left(18^{\text {th }}\right.$ edn), pp. 742-743.

7. National Neonatology Forum 2005.

8. John P Cloherty (1993) Manual of neonatal care. (6th Edn). Chapter Meconium Aspiration. Pediatr Clin North Am, pp. 383-387. 
9. Wiswell TE, Tuggle JM, Turner BS (1990) Meconium aspiration syndrome: Have we made a difference? Pediatrics 85(5): 715-721.

10. Wiswell TE, Bent RC (1993) Meconium staining and the meconium aspiration syndrome. Pediatr Clin North Am. 40(5): 955-981.

11. Neal J, Thomas, Michele L, Shaffer (2010) Defining acute lung disease in children with the oxygenation saturation index. Pediatr Crit Care Med 11(1): 12-17.

12. Sanofi-Synthelabo (2003) Primacor (milrinone lactate) injection prescribing information. New York, USA.

13. Shipley JB, Tolman D, Hastillo A 0 Milrinone: basic and clinical pharmacology and acute and chronic management: a review. Am J Med Sci 311(6): 286-291.

14. White CM, Chow MSS (1997) The role of positive ionotropic agents in severe congestive heart failure. Formulary 32: 255-266.

15. Gheorghiade M, Benatar D, Konstam MA (1997) Pharmacotherapy for systolic dysfunction: a review of randomized clinical trials. Am J Cardiol 80: 14-27.

16. Skrabal MZ, Stading JA, Behmer Miller KA (2000) Advances in the treatment of congestive heart failure: new approaches for an old disease. Pharmacotherapy 20(7): 787-804.

17. Felker GM, O'Connor CM (2001) Inotropic therapy for heart failure: an evidence-based approach. Am Heart J 142(3): 393-401.

18. Anderson JL (1991) Hemodynamic and clinical benefits with intravenous in severe chronic heart failure: results of a multicenter study in the United States. Am Heart J 121(2): 1956-1964.

19. Rettig GF, Schieffer HJ (1989) Acute effects of intravenous milrinone in heart failure. Eur Heart J 10: 39-43.

20. Hilleman DE, Forbes WP (1989) Role of milrinone in the management of congestive heart failure. DICP 23(5): 357-362.

21. Bedford Laboratories (2002) Milrinone lactate injection prescribing information. Bedford, $\mathrm{OH}$.

22. Sanofi-Synthelabo, Personal communication, New York, USA.

23. The American Heart Association (2005) Guidelines 2005 for cardiopulmonary resuscitation and emergency cardiovascular care. Circulation 112(1): 151-211.

24. Haraldsson SA, Kieler Jensen N, Ricksten SE (2001) The additive pulmonary vasodilatory effects of inhaled prostacyclin and inhaled milrinonein postcardiac surgical patients with pulmonary hypertension. Anesth Analg 93(6): 1439-1445.

25. Carcillo JA, Fields AI (2009) Review Clinical practice parameters for hemodynamic support of pediatric and neonatal patients in septic shock. Crit Care Med. 37(2): 666-668.

26. Stroshane RM, Koss RF, Biddlecome CE (1984) Oral and intravenous pharmacokinetics of milrinone in human volunteers. J Pharm Sci 73(10): 1438-1441.

27. McNamara PJ, Laique F, Muang In S, Whyte HE (2006) Milrinone improves oxygenation in neonates with severe persistent pulmonary hypertension of the newborn. J Critical Care 21(2): 217-222.

28. Wagner RS, Smith CJ, Taylor AM, Rhoades RA (1997) Phosphodiesterase inhibition improves agonist induced relaxation of hypertensive pulmonary arteries. J Pharmacol Exp Ther 282(3):1650- 1657.

29. Artman M, Kithas PA, Wike JS, Strada SJ (1988) Inotropic responses change during postnatal maturation in rabbit. Am J Physiol 255(2): $335-342$.

30. Binah O, Sodowick B, Vulliemoz Y, Danilo Jr P, Rosen M (1986) The inotropic effects of amrinone and milrinone on neonatal and young canine cardiac muscle. Circulation 73(3): 46-51.

31. Ross Ascuitto NT, Ascuitto RJ, Ramage D, McDonough KH (1991) The effects of milrinone in the neonatal pig heart. Cardiovasc Drugs Ther 5(6): 1011-1019.

32. Bassler D, Kreutzer K, McNamara P, Kirpalani H (2010) Milrinone for persistent pulmonary hypertension of the newborn. Cochrane Neonatal Reviews 11.

33. Bassler D, Choong K, McNamara PJ, Kirpalani H (2006) Neonatal persistent pulmonary hypertension treated with milrinone: four case reports. Biol Neonate 89(1): 1-5.

34. Doo Kyo In, Sung Wan Yang (2006) Experience of Milrinone Treatment for Persistent Pulmonary Hypertension of the Newborn. J Korean Soc Neonatol 13(2): 201-208.

35. McNamara PJ, Laique F, Muang In S, Whyte HE (2006) Milrinone improves oxygenation in neonates with severe persistent pulmonary hypertension of the newborn. J Critical Care 21: 217-222.

36. Kirpalani H (2016) Pharmacokinetic Study of Milrinone in Babies With Persistent Pulmonary Hypertension of the Newborn.

Your next submission with Juniper Publishers will reach you the below assets

- Quality Editorial service

- Swift Peer Review

- Reprints availability

- E-prints Service

- Manuscript Podcast for convenient understanding

- Global attainment for your research

- Manuscript accessibility in different formats

( Pdf, E-pub, Full Text, Audio)

- Unceasing customer service

Track the below URL for one-step submission https://juniperpublishers.com/online-submission.php 